UCRL- -88211

DE83 010819
UCRL 88211 PREPRINT

Conf-830406--53

THE INFLUENCE OF STEEL TYPE ON THE ACTIVATION AND DECAY OF FUSION-REACTOR FIRST WALLS

James A. Blink and George P. Lasche

This paper was prepared for presentation at the ANS 5th Topica7 Meeting on the Technology of Fusion Energy to be held in Knoxvilie, Tenn., April 26-28, 1983.

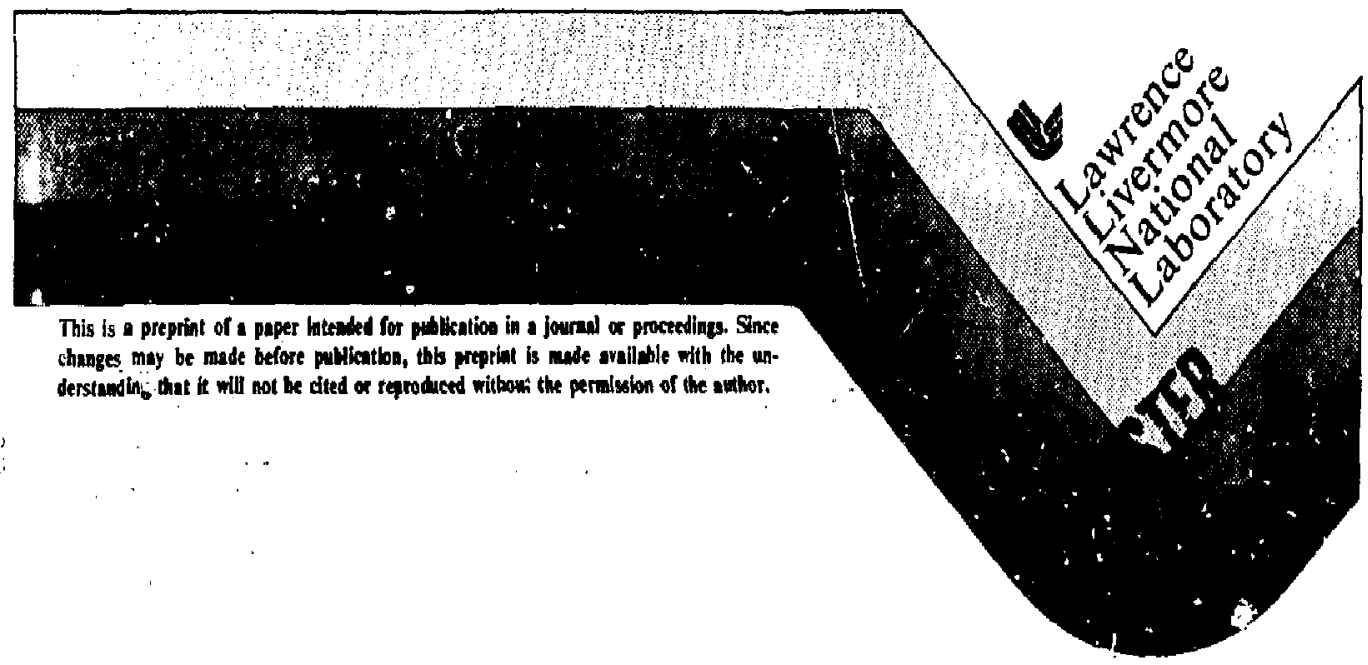


THE INFLUENCE OF STEEL TYPE ON THE

ACTIVATION AND DECAY OF FUSION-REACTOR FIRST WALLS*

\author{
3. A. Blink and G. P. Lasche \\ University of California \\ Lawrence Livermore Nationa? Laborotory \\ Livermore, CA 94550
}

\title{
ABSTRACT
}

Five steels (PCA, HT-9, thermally stabilized $2.25 \mathrm{Cr}-1 \mathrm{MO}$, Nb stabilized $2.25 \mathrm{Cr}-1 \mathrm{MO}$, and $2.25 \mathrm{Cr}-1 \mathrm{~V}$ ) are compared as a function of time from the viewpoints of activation, afterheat, inhalation biological hazard potential (bhp), ingestion bhp, and feasibility of disposa) by shallow land burial. An additional case uses the $2.25 \mathrm{Cr}-1 \mathrm{~V}$ steel with a liquid metal wall (LMW) protective shield between the neutran source and the wall. (This geometry is feasible for inertial confinement fusion reactors.) The PCA steel is the worst choice and the LMH protected $2.25 \mathrm{cr}-1 \mathrm{~V}$ is the best choice by substantial margins from all five viewpoints. The HT-9 and two versions of $2.25 \mathrm{cr}-1$ Mo are roughly the same at intermediate values. The $2.25 \mathrm{Cr}-1 \vee$ has about the same afterheat as those three steels, but its waste disposal feasibility is considerably better. Under NRC's proposed low level waste disposal rule (10CFR61), only the $2.25 \mathrm{Cr}-1 \vee$ could be considered low level waste suitable for shallow land burial.

INTROOUCTION

Fusion has long been touted as a radiologically clean alternative to fission power generation. Although fusion does not have the design problem of preventing afterheat from rearranging a large fuel supply into

\footnotetext{
* Work performed under the auspices of the U,S. DOE by Lawrence Livermore National Laboratory under contract No. W-7405-ENG-18.
} 
an uncontrolled energy producing mass, D-T fusion neutrons wtll be much wore energetic than fission neutrons. Furthermore, in most fusion reactor uesigns, the fusion neutrons are unmoderated when they reach the reactor wall, and host of high energy reactions becomes important. Consequently, fission activation codes and Jata libraries must be modified before being applied to fusiun reactor geometries.

Fusion wall materials have traditionally been chosen from temperature, atomic number, strerıth, and corrosion viewpoints. In this paper, we compare five stee?s from the viewpoint of activation. Because the rasults vary considerably with steel type, we believe that earlier attention must be given to alloy selection; perhaps even to the point of isotopically tailoring some of the constituents.

\section{METHODS OF CALCULATION}

In a fusion reactor wall, there are a large number of nucilides, the activation and decay equations for many of the nuclides are coupled, both the neutron flux and cross sections yary with neutron energy, and the neutron flux varies with location. Hence, the problem is well suited for the use of computer codes which calculate the activity of each nuclide as a function of time.

The procedure for determining the radioactive build-up and decay in each fusion reactor configuration is to sequentially run three computer codes: a neutron transport code to produce energy and spatially resolved neutron fluxes, a cross section collapsing code to produce flux-weighted, energy-averaged activation cross sections, and an activation/decay code. to solve the coupled rate equations as a function of time.

The neutron flux as a function of position and energy is calculated by the TART monte carlo neutron transport code. ${ }^{1}$ The output is in a file that can be read directly by the cross section collapsing code, ORLIB. ${ }^{2}$ ORLIB also requires the ACTL energy resolved cross section library, ${ }^{3}$ a brief instruction file specifying the location at which the flux is to be read, the neutron source strength, and the nuclides for which the cross sections are to be averaged. The output is a set of three cross section files; the first two files are read directiy by the 
FORIG activation/decay code ${ }^{4}$ and the third file is used as input to post-processing hand calculations that are sometimes useful in explaining the FORIG resuits.

The FORIG code is an adaptation for fusion reactor problems of the ORIGEN2 code..$^{5}$ The ba. ic changes are to read 11 rather than 6 standard reactions, and to allow up to 15 rather than 7 pathways for activation o: decay of each nuclide. FORIG produces output in the same format as ORIGEN2; composition, activity, thernal power, inhalation biological hazard potential (bhp), ingestion bhp, chemical ingestion bhp, and garma spectrum can be printend as a function of time for each nuclide or element. Also, both the total values or the fractional values of each quantity are available as a function of time.

The ACTL library and the TART, ORLIB, and FORIG codes are all available on the LLNL Octopus network and on the MFECC network. In addition, ORLIB, FORIG, and ACTL are being sent to the Radiation Shielding Information Center (RSIC) at Oak Ridge National Laboratory. The ACTL library has been recently updated by Howerton for fusion reactor calculations. "A list of the nuclides and reactions in the library is available from the authors, Additional nuclides and reactions will be added on request.

In analyzing the results of the computer codes, it is sometimes necessary to determine the principal sequences of reactions and decays responsible for the presence of important radionuclides. In addition, it is necessary to determine if the generation of nuclides not found in the computer decay library can be neglecteo. These and similar problems in analyzing computational results are addressed using analytical estimation techniques previously described by Lasche. ${ }^{7}$ Use of these hand calculations has also given us confidence in the FORIG calculations.

\section{STEEL COMPOSITIONS INYESTIGATED}

Several steels have been used in fusion reactor design studies (Table 1). Primary Candidate Ailoy, also called PCA (case N), is an advanced titanium modified type 316 stainless steel under consideration for first walls in magnetic fusion reactors. It was the material 
Table 1. Materials Investigated. All compositions are in wt.\%.

\begin{tabular}{|c|c|c|c|c|c|}
\hline \multirow[b]{2}{*}{ Element } & \multicolumn{5}{|c|}{ Case } \\
\hline & $\mathrm{PCA}^{N}$ & $\stackrel{0}{H T-9}$ & $\begin{array}{c}P \\
\text { Nb } \\
\text { stabilized } \\
2.25 \mathrm{Cr} \\
\end{array}$ & $\begin{array}{c}0 \\
\text { Thermally } \\
\text { stabilized } \\
2.25 \mathrm{Cr}\end{array}$ & $\begin{array}{c}R \text { and } S \\
\text { Case P with } \\
V \text { replacing Mo }\end{array}$ \\
\hline B & 0.005 & - & $=$ & $=$ & - \\
\hline C & 0.05 & 0.22 & 0.09 & 0.11 & 0.11 \\
\hline$N$ & 0.01 & - & - & - & - \\
\hline Al & 0.03 & - & - & - & - \\
\hline Si & 0.5 & 0.38 & 0.32 & 0.25 & 0.25 \\
\hline$p$ & 0.01 & 0.079 & 0.012 & 0.005 & 0.005 \\
\hline s & 0.005 & 0.006 & 0.007 & 0.011 & 0.011 \\
\hline$T_{i}$ & 0.3 & - & - & - & - \\
\hline$v$ & 0.1 & 0.27 & - & - & 0.94 \\
\hline $\mathrm{Cr}$ & 14 & 11.3 & 2.19 & 2.22 & 2.22 \\
\hline$M n$ & 2 & 0.52 & 0.46 & 0.41 & 0.47 \\
\hline $\mathrm{Fe}$ & 54.88 & 85.435 & 94.261 & 96.054 & 96.054 \\
\hline Co & 0.03 & - & 0.0011 & 0.002 & 0.002 \\
\hline Ni & 16 & 0.5 & 0.5489 & 0.0998 & 0.0998 \\
\hline cu & 0.02 & - & - & - & - \\
\hline As & 0.02 & - & - & - & - \\
\hline Nb & 0.03 & - & 1.13 & - & - \\
\hline Mo & 2 & 0.85 & 0.98 & 0.94 & - \\
\hline Ta & 0.01 & - & - & $=$ & - \\
\hline$W$ & - & 0.5 & - & 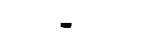 & - \\
\hline
\end{tabular}


selected for the STARFIRE cormercial tokamak design study. HT-9 (case 0) is a ferritic steel containing $12 \% \mathrm{Cr}$; it has been used in the HIBALL heavy ion ICF design, the EAGLE light ion ICF design, and the WITAMIR tandem mirror design. The low chromium ferritic steel, $2.25 \mathrm{Cr}-1 \mathrm{Mo}$, is extensively used in steam generators, and two variations have been investigated for use with liquid lithium. One version (case P) uses a small amount of Nb to stabilize the carbides against lithium corrosion. The other version, (case Q) which stabilizes the carbides with a heat treatment, is used in the HYLIFE laser or heavy ion ICF design. The 2.25 $[r-] \vee$ stee 1 (case $R$ ) is a modification to thermally stabilized 2.25 $\mathrm{Cr}-1$ Mo in which the Mo is replaced by $V$ to reduce the long term activity. Although this steel has not yet been evaluated from other viempoints (e.g. weldability or corrosion resistance), we include it to quantify its benefits from the viewpoint of activation. The low activating alloy, $2.25 \mathrm{Cr}-1 \mathrm{~V}$, was also used with an ICF source and a 75-cm liquid lithium wall (LMW) protection (case S).

The calculations were done in one-dimensional geometry for all five materials. In each case, the neutron source was on for 30 years at a flux corresponding to 1 GWe chamber power and 70\% capacity factor, and then the wall material was allowed to decay. The $14.1 \mathrm{MeV}$ point source was enclosed by the 2-cm-thick spherical wall at 5-m radius. The neutron b lanket/reflector consisted of $78 \mathrm{~cm}$ of lithium, $18 \mathrm{~cm}$ of graphite, $2 \mathrm{~cm}$ of boron carbide, and a 10-cm-thick outer wall. A companion paper, 8 investigates the influence of geometry (wall radius, wall shape, distributed vs point source, etc.) on first wall activation.

\section{NUMERICAL RESULTS}

The activity is shown as a function of time in Fig. 1 . The linear-linear form is used to present an undistorted visual comparison, because the apparent relative magnitudes in logarithmic form can be made large or small by the choice of the upper and lower cutoff decade. However, the linear scale has the disadvantage of not showing relative magnitudes at long decay times, and for this reason we have expanded that 


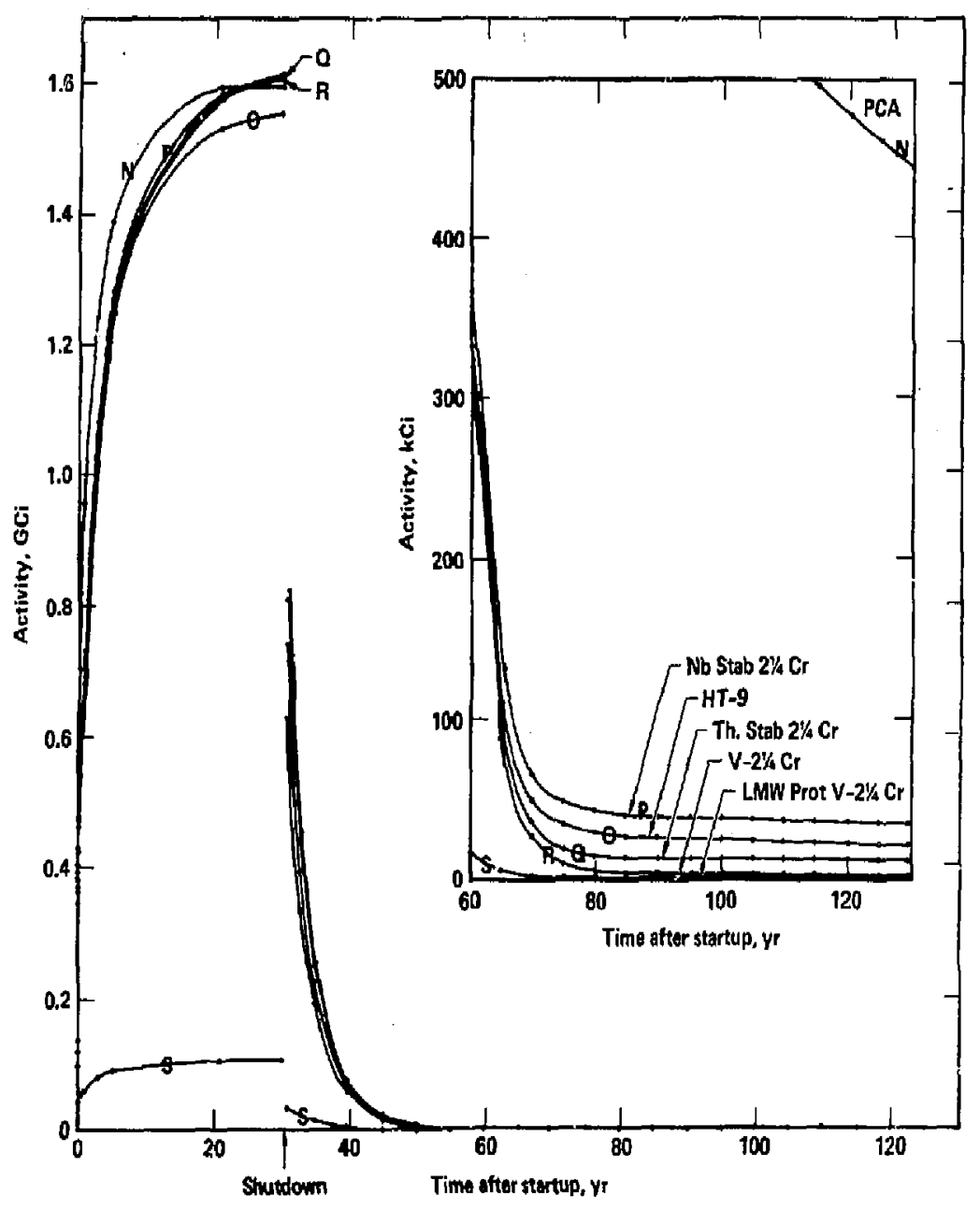

Fig. I Activity as a function of time. 
portion of the linear scale in the inset in Fig. I. We haye also generated a semilog plot to allow easy extraction of numerical values at all times of interest, and to allow estimation of the effective decay half life as a function of time from the slope of the decay curve, but space does not permit its use here.

At shutdown, all five unprotected walls have roughly equal activities $21.6 \mathrm{GCi}$, and the LMW protected wall has a factor of 16 less activity. Ten years after shutdown, the activity of each wall has dropped by a factor of $a 30$, and the five unprotected walls still have roughly equal activities.

Fifty years after shutdown (80 years after startup), a considerable spread has developed between the six cases as shown in Table 2. The PCA wall (case $N$ ) is by far the worst with an activity of $650 \mathrm{kCi}$, a factor of 2400 reduction from shutdown. The two versions of $2.25 \mathrm{Cr}-1$ Mo and the HT- 9 (cases $0, P$, and $Q$ ) have activities of a few tens of $\mathrm{kCl}$. The two $2.25 \mathrm{Cr}-1 \mathrm{~V}$ walls (cases $R$ and $S$ ) have activities of only a few $\mathrm{kCi}$. Also, the LMW-protected $2.25 \mathrm{Cr}-1 \mathrm{~V}$ wall (case S) activity is now over 400 times less than the PCA activity; it was only 16 times less at shutdown.

At 50 to 100 years after shutdown, all six cases have roughly equal effective decay rates. The slight difference for each material is because different nuclides are dominant. At 100 years after shutdown, ${ }^{63} \mathrm{Ni}$ is the shortest lived isotope still present in all six cases $(92$ year half 7 ife). As ${ }^{63}$ Ni decays away, ${ }^{93}$ Mo (2980 year half life) will deminate except for the two Mo-free walls (cases $R$ and $S$ ). In these cases, ${ }^{59} \mathrm{Ni}\left(80,000\right.$ year half life) and ${ }^{53} \mathrm{Mn}(3,800,000$ year half life) will dominate. However, all the steels have roughly equal amounts of ${ }^{5.3} \mathrm{Mn}$ since they all contain similar amounts of the parents, Fe and Mn. (The only exception is for the LMW-protected wall where the ${ }^{53} \mathrm{Mn}$ activity is 240 times lower due to the softer flux.) Similarly, although ${ }^{59} \mathrm{Ni}$ does not show on fractional activity plots for the Mo-containing steels because it is swamped by the ${ }^{63} \mathrm{Ni}$ and ${ }^{93} \mathrm{Mo}$ activities, its actual activities are higher than in the Mo-free steel. For both ${ }^{63} \mathrm{Ni}$ and ${ }^{59} \mathrm{Ni}$, the parents are $\mathrm{Ni}$ isotopes. The ratios of the activities of these isotopes to the initial nickel population are 
Table 2. Activity 50 Years After Shutdown. The final two columens show the reduction of activity compared to shutdown and compared to PCA (50 yrs after shutdown).

\begin{tabular}{|c|c|c|c|c|}
\hline Case & Description & $\begin{array}{l}\text { Activity } 50 \text { yrs } \\
\text { after shutdown } \\
\end{array}$ & $\begin{array}{l}\text { Reduction } \\
\text { since } \\
\text { shutdown }\end{array}$ & $\begin{array}{l}\text { Reduction } \\
\text { from PCA }\end{array}$ \\
\hline N & PCA & $650 \mathrm{kCj}$ & 2,400 & 1 \\
\hline 0 & HT-9 & $30 \mathrm{kCi}$ & 52,000 & 22 \\
\hline $\mathrm{p}$ & Nb stab. $2.25 \mathrm{cr}$ & $44 \mathrm{kCi}$ & 36,000 & 15 \\
\hline \multirow[t]{2}{*}{$Q$} & Thermally stab. & & & \\
\hline & $2.25 \mathrm{Cr}$ & $16 \mathrm{kCj}$ & 100,000 & 41 \\
\hline$R$ & $2.25 \mathrm{Cr}-1 \mathrm{~V}$ & $5.5 \mathrm{kCi}$ & 293,000 & 119 \\
\hline \multirow[t]{2}{*}{$S$} & LMN protected & & & \\
\hline & $2.25 \mathrm{Cr}-1 \mathrm{~V}$ & $1.6 \mathrm{kCi}$ & 60,000 & 412 \\
\hline
\end{tabular}


Constant to within a few percent for all five unprotected steels. Similarly, the ratio of ${ }^{93}$ Mo activity to initial Mo mass is constant to within $0.5 \%$ for all four Mo-containing walls. In the Nb stabilized $2.25 \mathrm{Cr}-1$ Mo steel, ${ }^{94} \mathrm{Nb}(20,300$ year half life) will also be important at long times. In all six cases, tritium has been eliminated from consideration because the tritium that diffuses into the steel during operation is much more significant than the tritium produced in the steel by neutron reactions. 9

Inspection of the FORIG output also revealed the importance of accounting for the activation of daughters and for changes in parent nuclide populations. In one example, the ${ }^{55_{M n}}$ inventory tripled during 30 years of activation, and its activation daughters would be underestimated if the initial population was used in a hand caiculation.

The afterheat in the six walls is shown as a function of time in Fig. 2. If a peak temperature of $1300 \mathrm{~K}$ is allowed, the spherical chamber can be burieo in earth when its afterheat is $274 \mathrm{~kW}$ if it is first crushed or $261 \mathrm{~kW}$ if it is buried as a hollow sphere. 10 Assuming hollow sphere burial, the PCA wall cannot be buried until 24 years after shutdown, the other four unprotected walls until 9 years after shutdown, and the LMW protected wail until 3 years after shutdown. For crushed sphere burial, the PCA wall must be held for 36 years after shutdown, the other four unprotected walls for $~ 214$ years, and the LMW protected wall for 5 years.

The inhalation biological hazard potential (bhp) is shown for the six walls in Fig. 3. This index represents the amount of air required to dilute a fully vaporized wall such that the dose received by continuousiy breathing the mixture will not exceed 0.5 rem per year. The inhalation thp is calculated for each nuclide by dividing the activity by the radioactivity concentration guide (RCG) taken from column 1 of Table I! of IOCFR20 (Part 20, Title 10, Code of Federal Regulations). Since structure vaporization is only possible by applying large amounts of energy, inhalation ohp is only appropriate at sliutdown or shortly thereafter. Three of the steels (HT-9, thermally stabilized $2.25 \mathrm{Cr}$, and $2.25 \mathrm{Cr}-1 \mathrm{~V}$ ) have roughly equal shutdown inhalation bhp's of $\imath 3 \times 10^{8} \mathrm{~km}^{3}$. The PCA and $\mathrm{Nb}$ stabilized $2.25 \mathrm{Cr}$ walls are about 


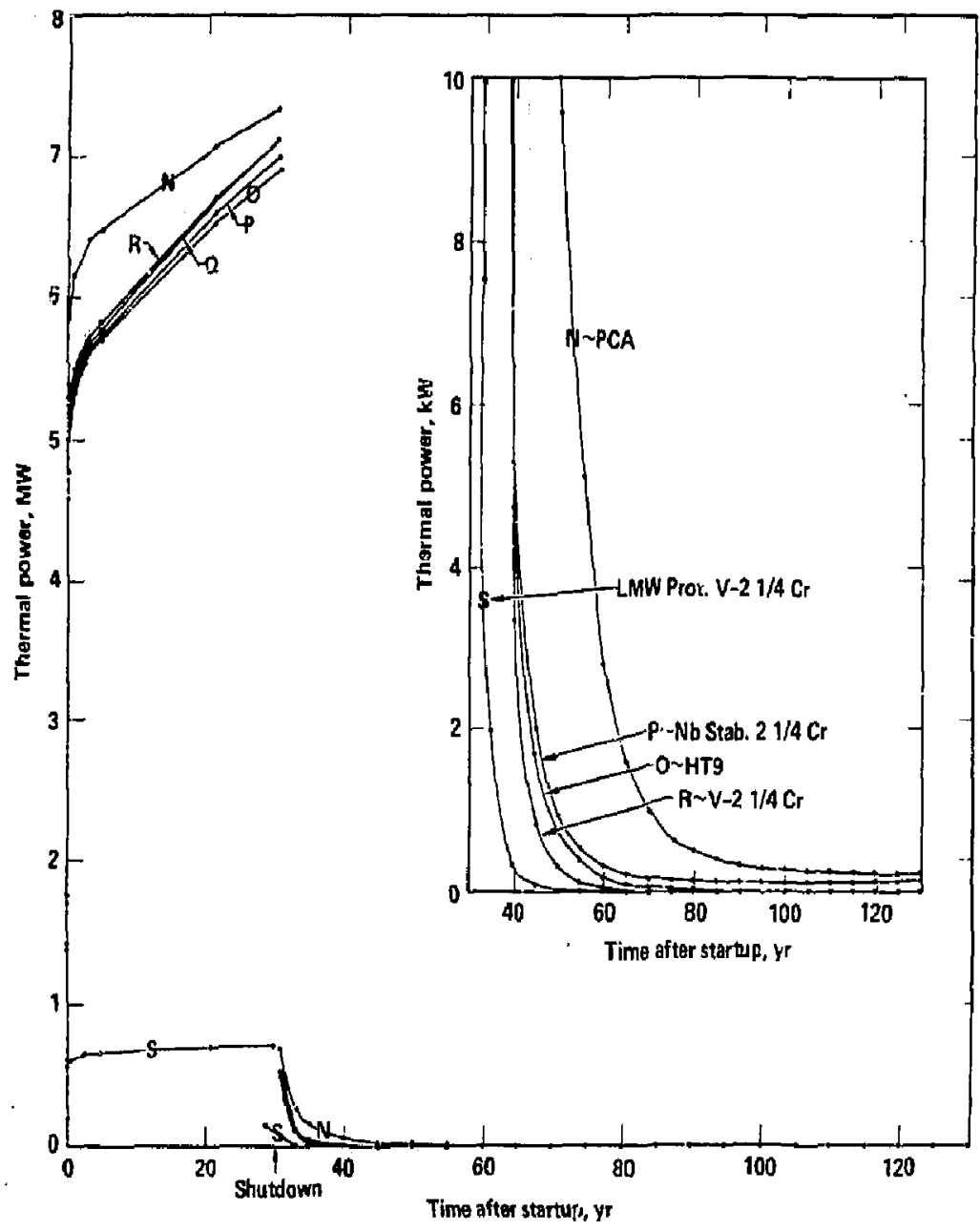

Fig. 2 Afterheat as a function of time. At $61 \mathrm{~kW}$, the peak temperature of a buried hollow sphere wall would be $1300 \mathrm{k}$. 


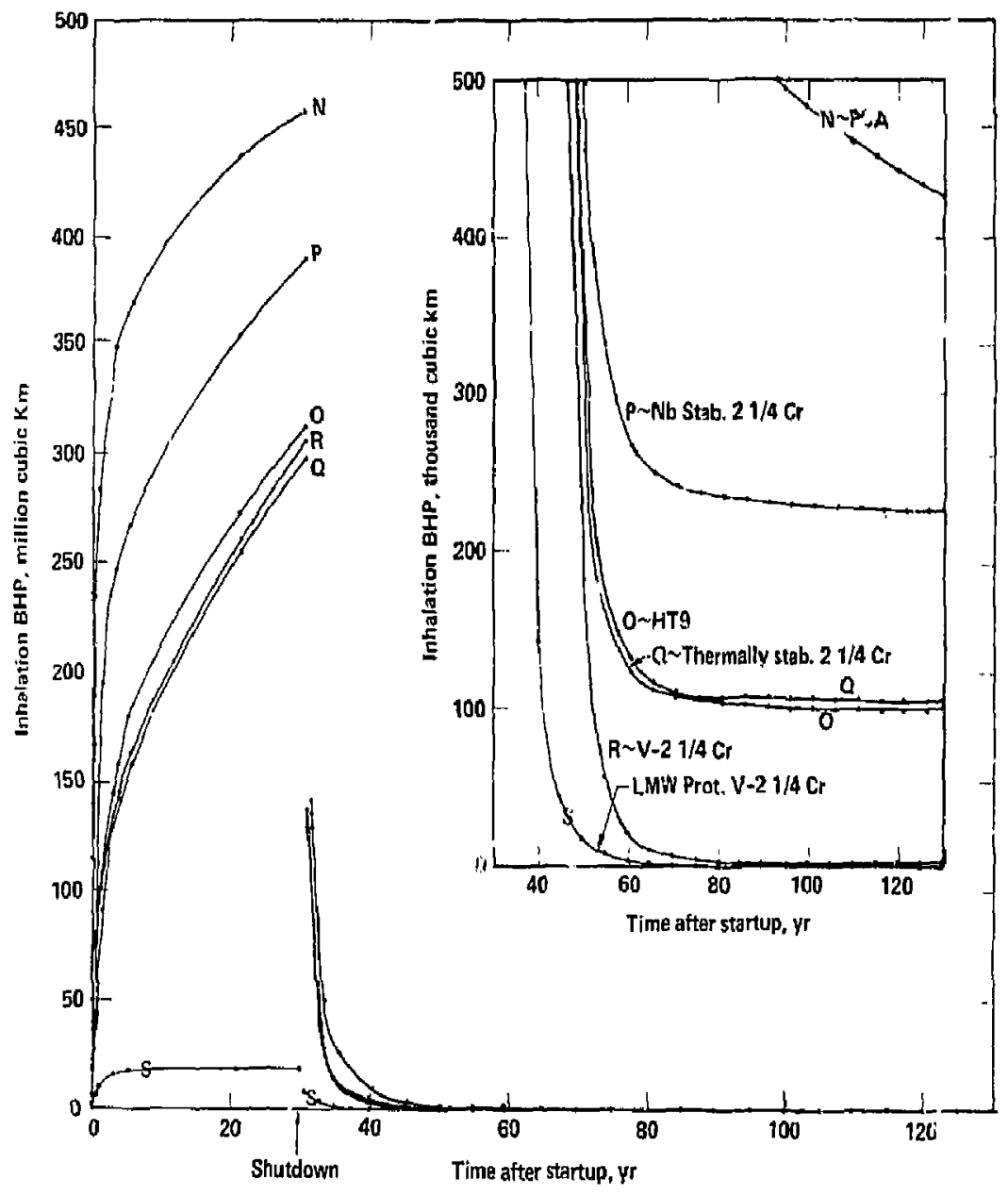

Fig. 3 Inhalation bhp as a function of time. 
25\% and 50\% higher, respectively, while the LWN protected $2.25 \mathrm{Cr}-1 \mathrm{~V}$ is a factor of 15 lower.

The ingestion bhp is the amount of water required to dilute a fully dissolved wall to the level that the dose received by drinking only this water will not excecd 0.5 rem per year. The ingestion bhp is calculated by using the RCG values taken from column 2, Table II, 10CFR?0. Dissolution of the wall into water is most likely after the material is buried (as waste). The ingestion bhp is shown for the six walls in Fig. 4. The data are normalized as a ratio of the radioactive ingestion thp of the activated wall to the amount of water required to dilute an unactivated wall, from a chemical hazard viewpoint. Thus, when the normalized blip falls to 1.0, dissolution of the activated wall is no worse than dissolving pure, clean steel. After only 15 and 28 years, the LMW protected and unprotected $2.25 \mathrm{cr}-1 \mathrm{~V}$ walls reach the level where the radioactive hazard of shallow land burial is identica! to the routinely accepted chemical hazard of burying unirradiated steel. The other four walls reach roughly steady bhp values at $\imath 35$ years after shutdown. The HT-9 and thermally stabilized $2.25 \mathrm{Cr}$ level is $\sim 4$, the $\mathrm{Nb}$ stabilized $2.25 \mathrm{Cr}$ steady level is 29 , and the $\mathrm{PCA}$ wall reaches a level of 220 .

Tha ratios of radioactive to chenical ingestion bhp's at $\sim 35$ years after shutduwn iridicate that shallow burial might be feasible at that time. However, NRC has recently addressed the shallow burial issue in a new regulation, 10CFR5l. This regulation lists the maximum allowable concentration of each nuclide in the solid waste (rather than in water or air). The actual concentrations are divided by the allowable concentrations, and the ratios are summed over all nuclides. The resulting sum (called the shallow burial index or SBI) must be less than 1.0 before burial is allowed. This technique has been applied to our six steels at a time of 50 years after shutdown. The values of PCA, HT-9, and both thermally and niobium stabilized $2.25 \mathrm{Cr}$ steels are over 100 times above the proposed limits (due to the low allowable ${ }^{94} \mathrm{Nb}$ limit). The unprotected and LAN protected $2.25 \mathrm{Cr}-1 \mathrm{~V}$ wal?s have indices of 0.14 


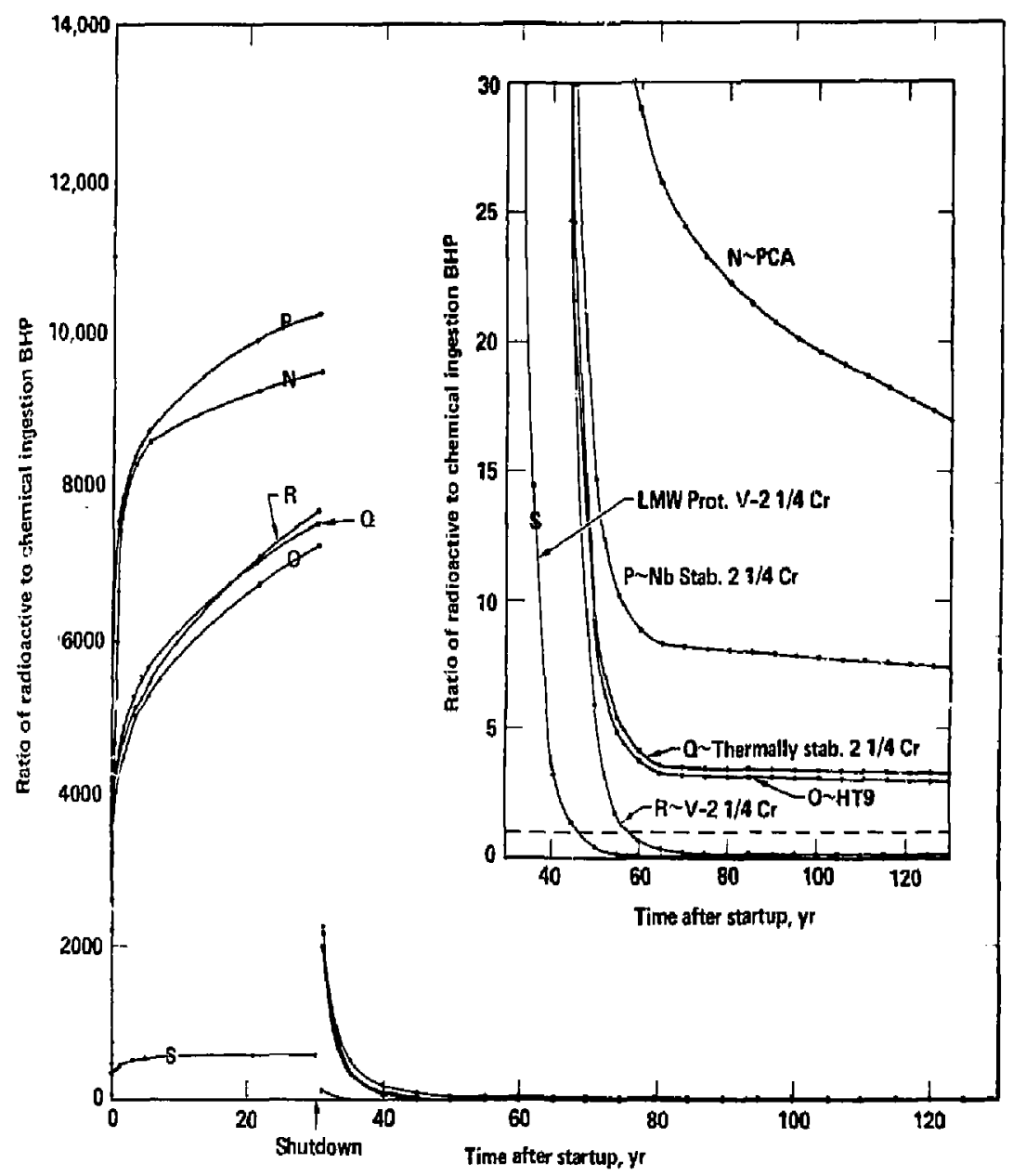

Fig. 4 Ingestion bhp as a function of time. The ratio plotted compares the radiological ingestion bhp to the initial (unirradiated) chemical ingestion bhp. 
and 0.6 , respectively. Thus; only the $2.25 \mathrm{Cr}-1 V$ walls could be buried fifty years after shutdown under the proposed rules. Since LMW protection would also reduce ${ }^{94}$ production in the other steels due to the softer and less intense neutron flux, Liw inertial fusion reactors will have a significant advantage over magnetic fusion reactors from the viempoint of structural waste disposal.

The discrepancy between the ingestion bhp and the shallow burial index is disturbing. The contribution of ${ }^{94} \mathrm{Nb}$ to the SBI is about 2500 times its contribution to the normalized ingestion bhip. The proposed revision of 1OCFR20 has an even higher ingestion RCG for ${ }^{94} \mathrm{Nb}$, and the discrepancy will increase to a factor of 50,000. Conversely, the contribution of ${ }^{93} \mathrm{MO}$ to the SBI is only about $10 \%$ of its contribution to the normalized bhp; this is because ${ }^{137}$ Cs was used as a surrogate for ${ }^{93} \mathrm{MO}_{\mathrm{O}}$ as in the draft 10CFR61. We believe that 10CFR61 must be expanded to include more nuclides, and that the ${ }^{94_{N b}}$ discrepancy between 10CFR61 and 10CFR20 must be resolved by the RRC.

\section{COMPARISON OF THE SIX STEELS}

The PCA steei appears to be a poor choice from both afterheat and disposal viewpoints. The HT-9 and both thermally and Nb stabilized 2.25 $\mathrm{Cr}$ steels are better from an afterheat viewpoint, but still unacceptable with respect to waste disposal. The unprotected $2.25 \mathrm{Cr}-1 \mathrm{~V}$ has about the same time required to reduce the afterheat to an acceptable level, and it is acceptable for shallow burial. The liquid metal wall protected $2.25 \mathrm{Cr}-1$ Y steel was by far the best of the six cases, with a short cooling time and legal disposal by shallow burial.

\section{REFEREMCES}

1. E. F. PLECHATY and J, R, KIMLINGER, TARTNP: A Coupled Neutron-Photon Monte Carlo Transport Cede, Lawrence Livermore National Laboratory, Livermore, CA, UCRL-50400, Vol. 14 (July 4, 1976).

2. J. A. BLINK, R. E. DYE, and J. R. KIMLINGER, QRLIB: A Computer Code that Produces One-Eneroy Group, Time- and Spatially-Averaged Neutron Cross Sections, Lawrence Livermore National Laboratory, Livermore, CA, UCR!-53262 (1981). 
3. M. A. GARDNER and R. J. HOWERTON, ACTL: Evaluated Neutron Activation Cross Section Library-Evaluation Techniques and Reaction Index, awrence Livermore National Laboratory, Livermore, CA, UCRL-50400, Vol. 18 (0ct. 17, 1978). In 1981, R. Howerton expanded the ACTL library to allow treatment of fusion reactor structural materials.

4. J. A. BLINK, FORIG: A Modification of the ORIGEN2 Isotope Generation and Depletion Code for Fusion Problems, Lawrence Livermore National Laboratory, Livermore, Ca, UCRL-53263 (Dec. 1981).

5. A. G. CROFF, A User's Manual for the ORIGEN2 Computer Code, Cak Ridge National Laboratory, Oak Ridge, TN, ORNL/TM-7175 (July 1980). Also published as Radiation Shielding Information Center Report CCC-37i.

6. R. J. HOWERTON, Lawrence Livermore National Laboratory, private communication (Dec. 1982).

7. G. P. LASCHE, "Estimates of Neutron-Induced Radionuclide Populations," Nuclear Science and Engineering, 83, 162 (1983).

8. G. P. LASCHE and J. A. BLINK, "The Dependence of Neutron-Induced Radioactivity in Fusion Reactors on Geometric Design Parameters," accepted for presentation at the 5th Top. Mtg. on the Tech. of Fusion Energy, Knoxville, TN, Apriा 26-28, T983. ATs0 UCRL-88212.

9. J. BLINK, Tritium in Fusion Reactor First Walls: Viffusion vs Transmutation, Lawrence Livermore National Laboratory, Livermore, $\overline{C A}$, Internat Memorandum, E\&MA 83-015 (1983).

10. J. A. BLINK, Afterheat Due to PbLi in a Pool-Type Reactor, Lawrence Livermore National Laboratory, Livermore, CA, Internal Memorandum, E\&HA 83-022 (1983).

This document wes prepared as an arcount of work sponsored hy an agency of the I nited Stales (jobernment, Neither the United States Government nor the Unitersity of California nor any of their employees, makes any warranis, express or implied, or assumes any legal liability or responsibility for the accuracy. completeness, or xyeluluess of any iufformation, appatutus, product, ar process disclosed, or aepresents that its use wotld not infringe privatsly owned rights. Relesence herein to eny specilic commercial products, process, or se rvice by trade name, trademark. manulacturer, of otherwise, does not necessarily constitute or imply its endorsement, recommendation, or faroring by the linited States Govemment or the University of Culifornin. The views and opiaions of authors expressed herein do not necessarily stale or reflect thase of the linited Stales Goventment therteof, and shall not be used for advertising or product endorsement purposes. 